\title{
Internal waves and temperature fronts on slopes
}

\author{
S. A. Thorpe ${ }^{1}$, U. Lemmin ${ }^{2}$ \\ ${ }^{1}$ SOES, Southampton Oceanography Centre, European Way, Southampton, SO14 3ZH, UK \\ Fax: + 441703 593059; e-mail: sxt@soc.soton.ac.uk \\ ${ }^{2}$ LRH, Ecole Polytechnique Fédérale de Lausanne, CH-1015, Lausanne, Switzerland
}

Received: 18 December 1998 / Revised: 7 April 1999 / Accepted: 22 April 1999

\begin{abstract}
Time series measurements from an array of temperature miniloggers in a line at constant depth along the sloping boundary of a lake are used to describe the 'internal surf zone' where internal waves interact with the sloping boundary. More small positive temperature time derivatives are recorded than negative, but there are more large negative values than positive, giving the overall distribution of temperature time derivatives a small negative skewness. This is consistent with the internal wave dynamics; fronts form during the up-slope phase of the motion, bringing cold water up the slope, and the return flow may become unstable, leading to small advecting billows and weak warm fronts. The data are analysed to detect 'events', periods in which the temperature derivatives exceed a set threshold. The speed and distance travelled by 'events' are described. The motion along the slope may be a consequence of (a) instabilities advected by the flow (b) internal waves propagating along-slope or (c) internal waves approaching the slope from oblique directions. The propagation of several of the observed 'events' can only be explained by (c), evidence that the internal surf zone has some, but possibly not all, the characteristics of the conventional 'surface wave' surf zone, with waves steepening as they approach the slope at oblique angles.
\end{abstract}

Key words. Oceanography: general (benthic boundary layers; limnology) - Oceanography: physical (internal and inertial waves)

\section{Introduction}

The processes important in the 'internal surf-zone', the region where internal waves break or reflect from the continental slope or the sloping boundaries around

Correspondence to: S. A. Thorpe lakes, are poorly known in spite of the inferred importance of this region in diapycnal mixing (e.g. see Ledwell and Hickey, 1995; Eriksen, 1998) and, for example, nutrient transfer to the epilimnion of lakes (e.g. MacIntyre et al., 1999). One characteristic is however well-established. Theoretical (Thorpe, 1987, 1999a), numerical (Slinn and Riley, 1996), ocean (Thorpe, 1992), lake (Lemmin et al., 1998) and laboratory (Thorpe, 1966, 1987; Dunkerton et al., 1998) studies have been made density variations caused by the reflection of internal waves from a boundary inclined at angle $\alpha$ to the horizontal in a fluid of uniform buoyancy frequency, $N$. All demonstrate the steepening of isopycnal surfaces in the phase of the wave in which water is moved up-slope. Fronts are therefore formed. They are most intense when the wave frequency is near the critical frequency, $N \sin \alpha$. The up-slope motion carries denser (usually colder) water from deeper levels up the slope, causing a rapid increase in density recorded at a fixed sensor.

Although internal fronts form even when waves reflect perfectly from a slope without dissipation, these fronts are akin to the sudden changes in surface level, the hydraulic jumps, which are always present in the surface wave surf-zone, and which (after the plunging of breakers) form the most spectacular phenomena and the most obvious 'signal' associated with the dissipation of waves approaching shore. Mixing occurs behind the fronts caused by internal waves, at least at the high Reynolds number flows in the natural environment. Time derivatives of temperature recorded at fixed points near the seabed have been observed to be negatively skewed (Thorpe et al., 1991), a possible consequence of the presence of the dense cold fronts. Theoretical work (Thorpe, 1999a) shows that in a uniformly stratified, constant buoyancy frequency fluid, fronts will be best developed for waves which propagate towards a slope at angles of incidence $<30^{\circ}$, and it is probable that the consequent mixing is most intense for such waves. The directional properties of waves dictate the strength of along-slope currents when waves break and lose 
momentum on a slope, whilst the spatial variation of incident wave direction may possibly be related to the generation of vortical modes and off-slope dispersion (Thorpe, 1998, 1999b).

The experiment described applies these ideas to the study of internal wave propagation onto a sloping boundary in a freshwater lake where the fronts caused by the waves are mainly associated with a rapid decrease in temperature.

\section{The experiment}

In August 1997 a linear array of 12 temperature miniloggers $54 \mathrm{~m}$ apart was deployed on the sloping subsurface side of Lake Geneva southeast of Ouchy. Each sensor was attached to a nylon line laid on the bottom at $30 \pm 3 \mathrm{~m}$ depth, following the bathymetric contours. The isobaths are aligned approximately eastwest in this area and the mean bottom slope, $\alpha$, is $10 \pm 2^{\circ}$. The sensor separation of $54 \mathrm{~m}$ was chosen to make it possible to identify the propagation of internal waves moving along the slope at speeds known, from earlier studies, to be of order $0.5 \mathrm{~ms}^{-1}$ or less (Thorpe et al., 1996, Thorpe and Jiang, 1998). Sensors sampled concurrently once a minute. Temperatures were recorded to $0.015^{\circ} \mathrm{C}$ resolution. The manufacturer's specification for the loggers' response time in a stirred fluid is 20 s. A submarine survey (see Thorpe et al., 1999) following the line of sensors two days after deployment found that, numbering sensors sequentially from west to east, the first pair of sensors and the 9th were hanging over gullies estimated to be $20-30 \mathrm{~m}$ wide and 5-10 m deep, and the 4th was covered by the fine sediment of the lake bed. All the others were lying well-exposed on the bottom.

Measurements were also made of the currents with an acoustic Doppler current meter (ADCM) $100 \mathrm{~m}$ west of sensor 1 of the minilogger array, and by Aanderaa current meters $1.7 \mathrm{~km}$ east and $2.3 \mathrm{~km}$ west of the ADCM, these accompanied by $25 \mathrm{~m}$ and $50 \mathrm{~m}$ Aanderaa thermistor chains, respectively, laid on the bottom down the slope. All instruments were close to, or spanned, the $30 \mathrm{~m}$ depth of the minilogger array. Unfortunately a $100 \mathrm{~m}$ Aanderaa thermistor chain normal to isobaths close to the array failed, reducing the directional information available at this site. Nevertheless, the data from the array prove informative. A methodology is developed to analyse the motion of waves, and possibly other phenomena, along sloping boundaries and hence to examine the physical processes involved in their interaction with the sloping boundary.

\section{Observations}

Figure 1 shows the temperatures measured by the array for a period of $2000 \mathrm{~min}$. These have been offset sequentially by $1{ }^{\circ} \mathrm{C}$ to show the temperatures from each sensor, 1-12, ordered from bottom to top. The temperatures of sensor 9 are low, presumably because it is hanging below the level of the others in a gulley. The weather had been fine and generally calm during the preceding period, with air temperatures ranging from 14.7 to $29.9^{\circ} \mathrm{C}$, and wind not exceeding $3.5 \mathrm{~ms}^{-1}$ for more than $3 \mathrm{~h}$. (Times are given in minutes after 1600 19th August, shortly after deployment.) A more persis-

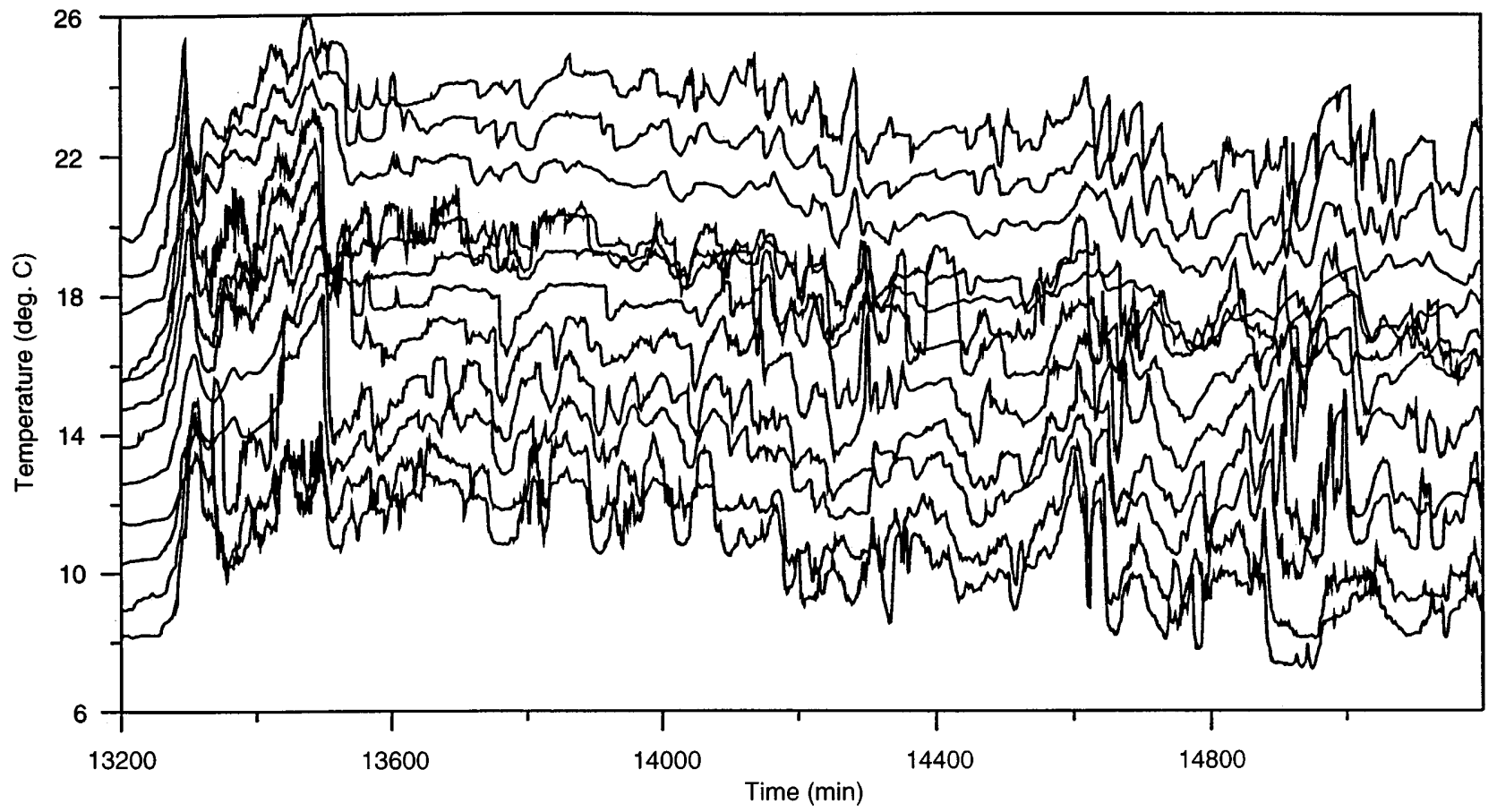

Fig. 1. Temperature recorded by the array of temperature miniloggers displaced sequentially by $1{ }^{\circ} \mathrm{C}$ and plotted from sensor 1 (bottom, at the west end of the array) to 12 (top) 
tent southeasterly wind reaching $6.7 \mathrm{~ms}^{-1}$ set in at $12000 \mathrm{~min}$, continuing until about $14520 \mathrm{~min}$, but it was sufficiently calm by $16800 \mathrm{~min}$ for instrument recovery to begin.

The most evident change in Fig. 1 occurs at about $13300 \mathrm{~min}$, with a temperature rise of about $4{ }^{\circ} \mathrm{C}$ occurring in about $35 \mathrm{~min}$. This rise is found to propagate westwards past the outlying Aanderaa instruments and through the array at about $0.5 \mathrm{~ms}^{-1}$. The abrupt temperature increase is characteristic of the internal surges or non-linear Kelvin waves travelling cyclonically around the lake (see Thorpe et al., 1996; Thorpe and Jiang, 1998) and which appear to be the dominant response to changes in wind forcing.

Conductivity, temperature and depth (CTD) profiles during the period up to $12000 \mathrm{~min}$ showed that the highest gradients in the thermocline were at $8 \mathrm{~m}$. The Aanderaa chains show that the water near $30 \mathrm{~m}$ was fairly uniformly stratified with a vertical gradient of about $0.064{ }^{\circ} \mathrm{C} \mathrm{m}^{-1}$ after the passage of the surge. This corresponds to a buoyancy frequency of $N=$ $6.4 \times 10^{-3} \mathrm{~s}^{-1}$ or $3.7 \mathrm{cyc} \mathrm{hr}^{-1}$, and a critical wave frequency on the slope of $0.64 \mathrm{cyc} \mathrm{h}^{-1}$.

\section{Analysis}

\section{The temperature variations}

Coherent temperature variations which affect all sensors can be detected in Fig. 1, e.g. at 13 750, 14900 min, and the surge at $13300 \mathrm{~min}$. The temperature variations are however rarely wavelike with well-defined oscillations, and generally signals are incoherent between neighbouring sensors. The mean slope of the temperature frequency spectra in the period following $13360 \mathrm{~min}$ (after the surge) is close to -2 in the range $0.8 \mathrm{cyc} \mathrm{h}^{-1}$ to the buoyancy frequency, $3.7 \mathrm{cyc} \mathrm{h}^{-1}$. Mean coherence between sensors exceeds 0.4 only for frequencies up to 2.5 cyc $\mathrm{h}^{-1}$ for sensor separations of $54 \mathrm{~m}$, and up to 1.3 cyc $\mathrm{h}^{-1}$ at $108 \mathrm{~m}$ separation. For greater separation coherence is only found for frequencies less than about $0.6 \mathrm{cyc} \mathrm{h}^{-1}$. Phase is generally close to zero where coherence is significant. It is however consistently negative near the critical frequency, indicating a westward propagation, and positive for frequencies between 0.7 and $1.5 \mathrm{cyc} \mathrm{h}^{-1}$ at $54 \mathrm{~m}$ separation, indicating mean eastward propagation at about $0.24 \mathrm{~ms}^{-1}$. Mean spectra at frequencies exceeding the buoyancy frequency have a slope near -2.5 . In this frequency range (but not in others) the mean spectra of sensors hanging over gullies is a factor of about 1.5 higher than those lying on the bottom.

The data were carefully examined to see when it was possible to identify temperature variations which could be followed between at least three minilogger sensors at near-constant time-delay, i.e. variations which move at uniform speed. In the $12000 \mathrm{~min}$ period preceding the surge only some 10 such 'events' could be found, one of them being that associated with the submarine's inspection of the array. This preliminary examination established that 'events' move in both directions along the slope and are most easily recognised by their temporal gradients. More frequent events are detected in the period of 2000 min following the surge when the amplitude of temperature variations are larger than in the earlier period, and this period of stronger winds was therefore selected for closer analysis.

\section{Temperature time derivatives}

As mentioned, density fronts form as internal waves propagate up a slope. In view of this physical relation to internal waves, the data are processed to identify large temporal gradients. An ad hoc (but later quantified) threshold of $0.15{ }^{\circ} \mathrm{C}$ over a period of $2 \mathrm{~min}$ for the absolute value of the temperature change is selected for recognition of 'events'. In the known vertical temperature gradient of $0.064{ }^{\circ} \mathrm{C}$, this corresponds to a vertical velocity of $1.95 \mathrm{cms}^{-1}$, or a movement of water up the $10^{\circ}$ slope at about $11.2 \mathrm{~cm} \mathrm{~s}^{-1}$.

Figure 2 shows the temperature time derivatives which exceed this threshold at the 12 sensors, each displaced sequentially by $0.5{ }^{\circ} \mathrm{C} \mathrm{min}-1$, for the period following the surge. Sensor 4, seen buried in the submarine survey, is as active as others after the surge has passed, whilst sensor 10 becomes notably less active. As shown later, the current speeds in the surge exceed $0.2 \mathrm{~ms}^{-1}$, a speed generally sufficient to mobilise soft fine sediment. Presumably sensor 4 is uncovered whilst 10 is partly covered by sediment when the surge passes by. Excluding sensors 4 and 10, the proportion of temperature gradients which exceed the threshold is 0.102 . (The corresponding figure for the whole recording period is 0.045 ; the gradients during the period prior to the surge are relatively small.)

Figure 3 shows a histogram of the temperature time gradients, $\mathrm{d} \theta / \mathrm{dt}$, averaged over the 6 sensors lying on the bottom (excluding 4 and 10) after $13320 \mathrm{~min}$. This period includes the rising temperature when the surge passes. The mean time derivative in the subsequent period as the temperatures return towards those before the surge (see Fig. 1) is about $1.3 \times 10^{-3}{ }^{\circ} \mathrm{C}$ min $^{-1}$, much smaller than the chosen threshold. The scale of proportions in Fig. 3 is logarithmic to show the values at large gradients. Near the origin the bias is towards positive time derivatives. The region $-0.1<\mathrm{d} \theta / \mathrm{dt}\left({ }^{\circ} \mathrm{C} \mathrm{min}^{-1}\right)<0$ has fewer values in each bin of the derivative range than the corresponding bins for $\mathrm{d} \theta / \mathrm{dt}>0$; there are $30 \%$ more gradients in the range 0.012 to $0.062{ }^{\circ} \mathrm{C} \mathrm{min}{ }^{-1}$ than between -0.062 and $-0.012{ }^{\circ} \mathrm{C} \mathrm{min}^{-1}$. About twice as many negative gradients are however found in each range bin when the modulus of the derivative exceeds $0.15 \mathrm{C} \mathrm{min}^{-1}$, giving the distribution an overall negative skewness of -0.05 .

\section{The propagation of 'events'}

The along-slope movement of time derivatives exceeding threshold (which will be referred to as 'events'), has been 


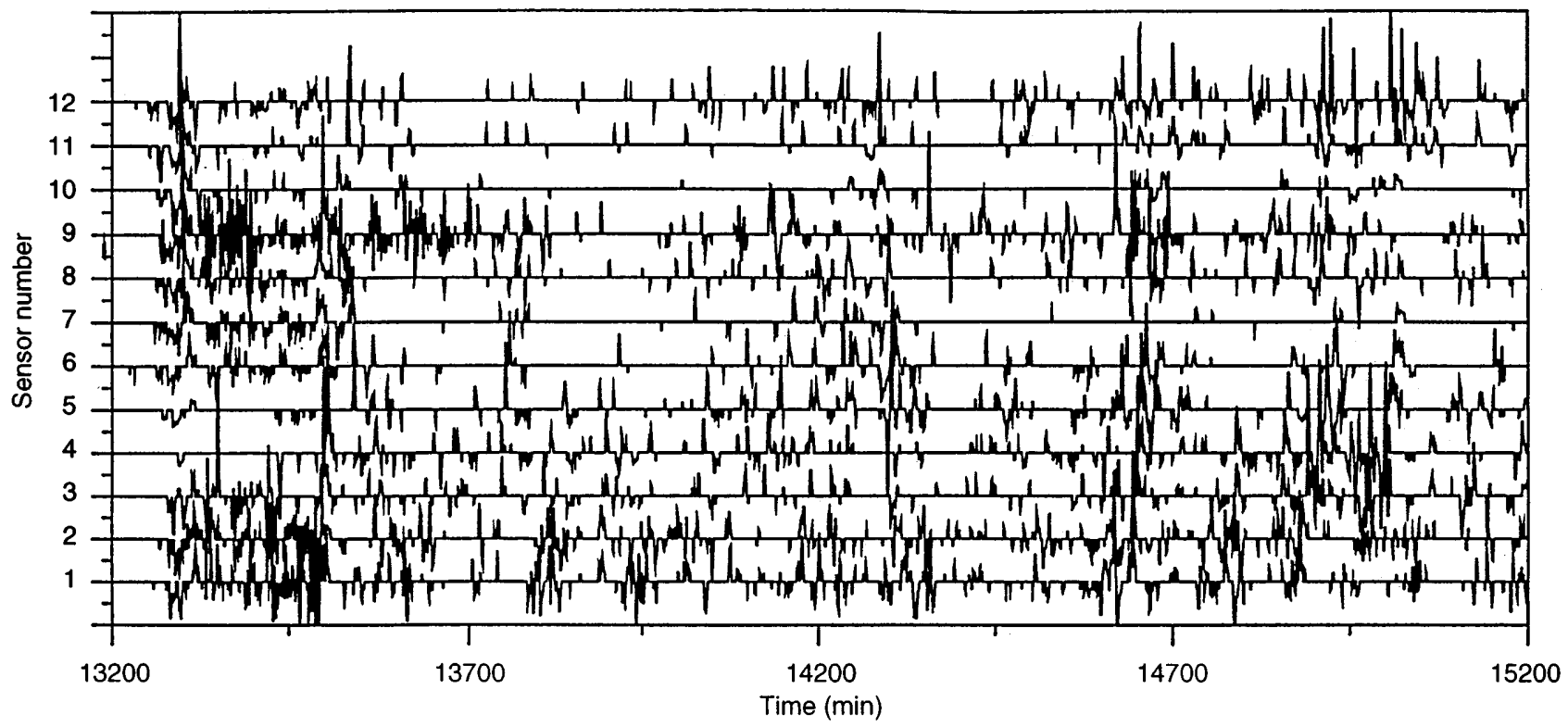

Fig. 2. Temperature time derivatives in the time period 13200 to 15200 min following the surge. Upwards displacements are values of negative gradients $<-0.15^{\circ} \mathrm{C} /(2 \mathrm{~min})$. Downwards are positive gradients $>0.15^{\circ} \mathrm{C} /(2 \mathrm{~min})$. Data from sensor 1 (lowest) to 12

measured in the period between 13200 and $15200 \mathrm{~min}$. This was first done by producing an expanded version of Fig. 2 and, wherever possible, drawing straight lines connecting all the 'events' which occur in sets of three or more consecutive sensors. (This was first done by hand and subsequently by a numerical program.) The lines indicate the propagation in space (the upward coordinate) and in time (the horizontal coordinate) of the events through the array. Their length, the number of sensors connected, minus one, times the interval between sensors, $54 \mathrm{~m}$, gives the distance travelled by events along the array. The slope of the lines, scaled by the sensor separation and the time interval of $1 \mathrm{~min}$, gives the speed at which events 'propagate' through the array. An arbitrary lower bound cut-off of $6.5 \mathrm{cms}^{-1}$ was used, equivalent to the time of $27.7 \mathrm{~min}$ for events

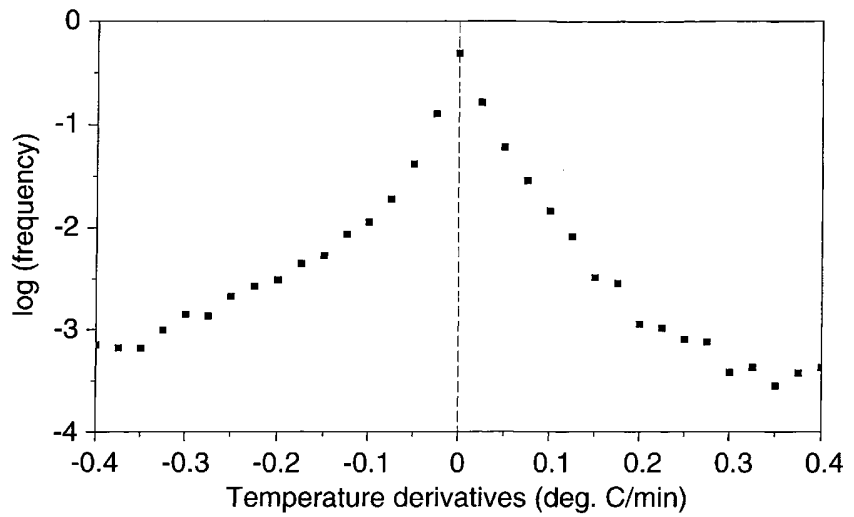

Fig. 3. Histogram of temperature time derivative, averaged over sensors 3, 5-8 and 11, for the period following the surge. The bin size (not shown) is $0.025^{\circ} \mathrm{C} / \mathrm{min}$ wide and the logarithm of the frequency is taken (the upper record) are sequentially displaced by $0.5^{\circ} \mathrm{C} / \mathrm{min}$ (i.e. the sensor separation corresponds to changes in temperature of $0.425{ }^{\circ} \mathrm{C}$ per min)

to propagate between three neighbouring sensors. The criteria used to identify moving events are therefore (a) the derivatives must exceed threshold and (b) values exceeding threshold must be found at at least three adjacent sensors. The length of movement along-slope must therefore be at least $108 \mathrm{~m}$, and the time delay between neighbouring sensors must be identical; derivatives exceeding threshold are not recognised as propagating events if the high gradient regions do not advance at constant speed. In practice this is not such a severe condition as it appears. The average time duration of high derivative regions is $3.1 \pm 0.3 \mathrm{~min}$ when the temperature is decreasing, and $2.83 \pm 0.3 \mathrm{~min}$ when the temperature is increasing. There is therefore some latitude in their time alignment but which has minimal affect on the subsequent analysis. The mean time duration of about $3 \mathrm{~min}$ for events in which gradients exceeded $0.075^{\circ} \mathrm{C} \mathrm{min}{ }^{-1}$ may, with the inferred water vertical speeds, be interpreted as vertical displacements of at least $3.52 \mathrm{~m}$, setting a lower limit to the amplitude of the disturbances causing them. About $3 \%$ of the high gradient periods at each sensor are associated with two events 'crossing' at different speeds.

The estimated speeds are shown as a function of time by the points in Fig. 4, together with the eastward component of the average current between 6 and $29 \mathrm{~m}$ off the bottom (solid line), and the maximum and minimum current components in the water column, measured by the ADCM. The currents are averaged over $1 \mathrm{~m}$ vertically and smoothed over $6 \mathrm{~min}$. The mean separation of high derivatives exceeding threshold at a given sensor (excluding those hanging and possibly covered by sediment) is $34.0 \mathrm{~min}$ and $30.4 \mathrm{~min}$, for decreasing and increasing temperatures, respectively. A total of 105 events were detected in the 2000 min period, 


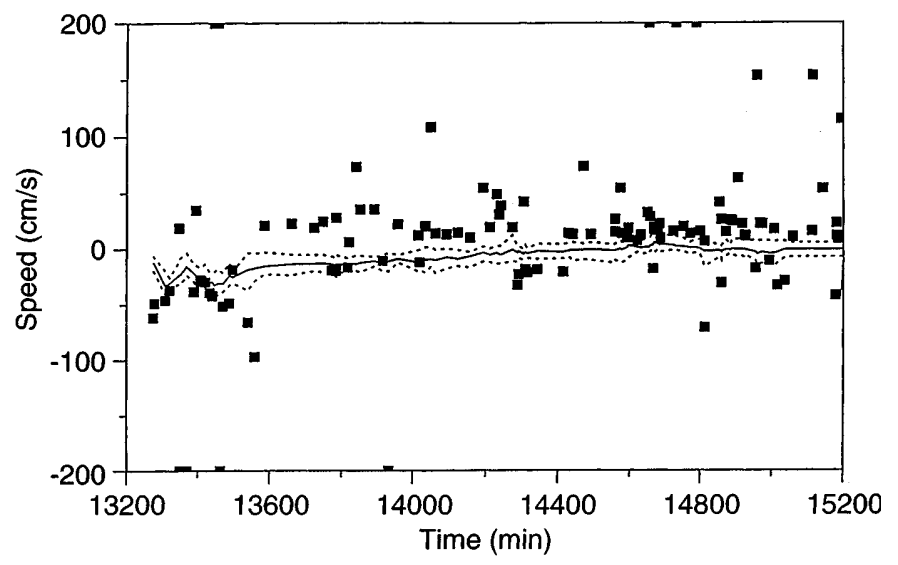

Fig. 4. The speed of 'events' (points) along the slope, the mean current between 6 and $29 \mathrm{~m}$ off the bottom (solid line), and the maximum and minimum currents (dashed), at times following the surge

giving an average time between detection of $19.5 \mathrm{~min}$. This is smaller than the mean separation of events passing a sensor; quite frequently two (or more) events were detected moving through the $594 \mathrm{~m}$ long array at different locations, sometimes in opposite directions.

Figure 5 is a histogram of the length of persistence of events as they move through the array. No values are recognised less than two sensor separations, $108 \mathrm{~m}$. Figure $5 \mathrm{a}$ is divided between events propagating to the east and west. The solid line in Fig. 5b shows the overall percentage of event lengths with squares and circles showing the corresponding percentages of positive and negative temperature derivatives, respectively. (The dashed line is described later.) Whilst the negative derivative events travel predominantly to the east, the positive are almost symmetrically divided east and west. Except during the passage of the surge, no events persist right through the full span of the array. This conclusion must however be qualified by recalling that at least one sensor was partly buried and consequently not capable of responding rapidly to temperature changes. In consequence, the possibility of following the movement of events is reduced at its position. Nevertheless, several events can be followed for $270 \mathrm{~m}$ along the slope. The average length travelled is $154 \mathrm{~m}$. The average time for which the events can be identified and followed as they travel through the array is $10.9 \mathrm{~min}$.

\section{Interpretation}

It will be assumed that advection by mean flow up and down the slope is negligible. Whilst the cross-slope current component is generally less than the along-slope flow, the maximum up-slope current component reaches $0.29 \mathrm{~ms}^{-1}$ and the down-slope $0.21 \mathrm{~ms}^{-1}$. Much of this motion may be attributable to the internal waves which produce the 'events'. (With a more extensive array of measurements of currents at the same location as the temperature measurements - the ADCM was $100 \mathrm{~m}$ from the end of the array - the relation of currents and
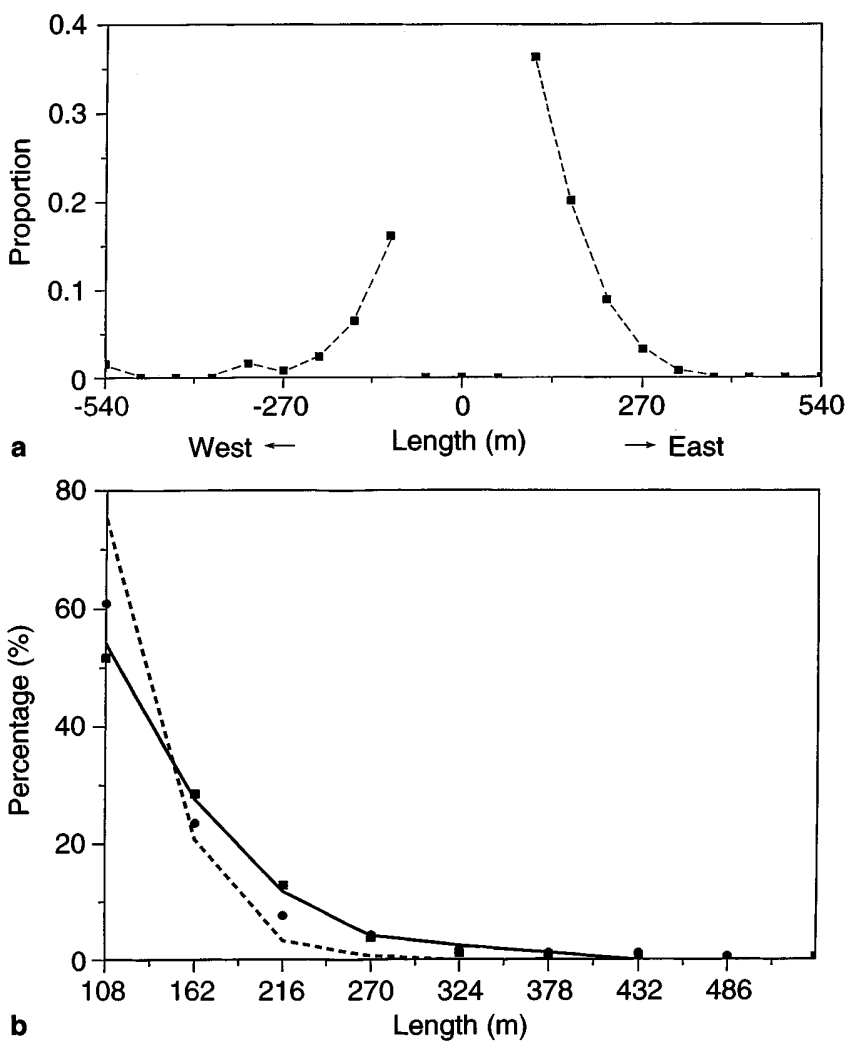

Fig. 5a, b. Frequency distribution of the length travelled by events along slope. The lengths are in multiples of $54 \mathrm{~m}$, the sensor separation. a Lengths with sign taken positive for events moving to the east, negative to the west; $\mathbf{b}$ lengths for (solid line) all data, positive temperature derivatives (squares) and negative derivatives (circles). The dashed line is the distribution for data with the same duration and number of events as the real data, but occurring at random times at each sensor

temperatures would help establish the field of internal waves and their relation to the events, e.g. see Thorpe and Jiang, 1998.)

The events may be classified into two types, those which propagate and satisfy condition (a) and condition (b), appearing sequentially and moving steadily between at least three neighbouring sensors, and those which satisfy (a) but appear at only one or two sensors or do not move steadily. The latter may be caused, for example, by local flow instability producing KelvinHelmholtz billows, by high gradients produced when two waves propagating from different directions collide near a sensor, by short-crested waves (of length $<168 \mathrm{~m}$ ) and moving up-slope and crossing only two sensor positions, or by a consequence of unsteady advection. It is the propagating events which are of most interest here. An average of $32 \%$ of the events satisfying condition (a) also satisfied (b).

The propagating event speeds fall into three classes. Class 1 . Some $(9.5 \%)$ of the propagating events shown in Fig. 4 have speeds which lie within the range of the along-slope current speed. It is possible that these are caused by the presence of instabilities growing in the shear flow, although it would be expected that, if of large vertical scale, they would advect at the mean 
current speed or, if local instabilities, that they would advect at the speed of the current near the bed. They may alternatively be internal waves of high vertical wave number (i.e. $\gg 2 \pi /$ water depth) propagating in the flow close to the bed. Events which have speeds outside the range of the along-slope flow cannot be a direct consequence of instability (see Banks et al., 1976); they appear to be internal waves.

Figure 6 shows the along-slope speed of events relative to the mean along-slope current, and the relative maximum and minimum currents. These relative speeds are fairly insensitive to the value of reference current; there is little difference to Fig. 6 (or to Fig. 8 which follows) if the flow relative to the mean along-slope current measured between 6 and $9 \mathrm{~m}$ off the bed is used instead of that between 6 and $29 \mathrm{~m}$. Events outside the range of relative flow can be divided into two further classes:

Class 2. Those which move slower than the fastest internal waves, $c_{\max }$. The surge appears to be a long wave, and is of the first (the lowest) internal wave mode: these have the greatest speed. Its speed through the array relative to the mean current, $0.493 \mathrm{~ms}^{-1}$, is therefore taken to characterise $c_{\max }$. This exceeds the speed of the currents relative to their mean, as it should unless the longest wave is of such amplitude that it carries a rotor i.e. a circulating patch of water, with it, or is in the unsteady condition of convective breaking (see Orlanski and Bryan, 1972). Events which have speeds greater than the current but less than $c_{\max }$ may be internal waves travelling along the slope which are of either the first mode, but of moderate wavelength, or higher mode.

Class 3. Events which have speeds greater than $c_{\max }$ cannot be caused by internal waves travelling parallel to the slope, but must be waves travelling with non-zero components up or down the slope. If their phase speed is $c$, then their angle of incidence is $\theta=\sin ^{-1}\left(c / c_{p}\right)$, where $c_{p}$ is the speed of lines of constant phase in the wave parallel to the isobaths, that is the speed along the line of sensors (see Fig. 7). But $c$ must be less than $c_{\max }$, and

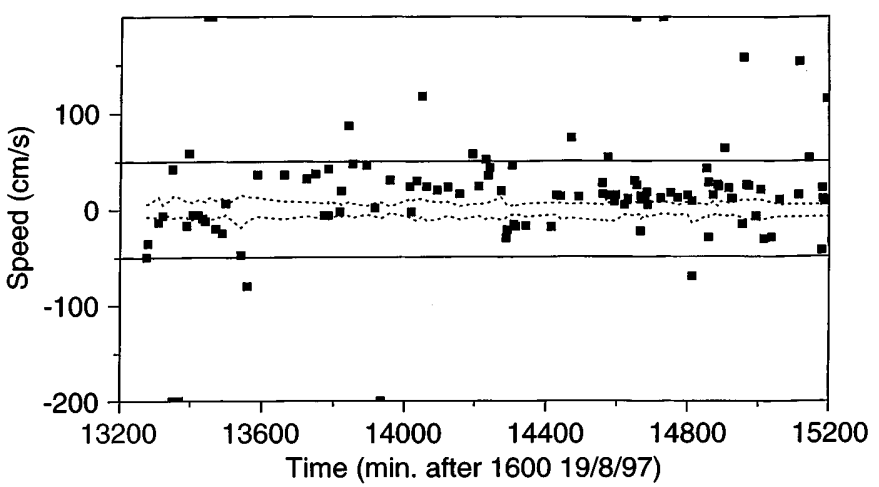

Fig. 6. The speed of events (points) and the maximum and minimum along-slope currents relative to the mean depth-averaged along-slope current. The lines at + or $-0.5 \mathrm{~ms}^{-1}$ indicate the range of speeds of waves propagating parallel to isobaths hence the maximum angle of incidence of the internal waves to the slope is

$\theta_{\max }=\sin ^{-1}\left(c_{\max } / c_{p}\right)$.

Twentyfive percent of the events have relative speeds, $c_{p}>c_{\max }$ and, for these, the angle $\theta_{\max }$ is calculated and shown in Fig. 8 at the times at which the events were observed. The angle $\theta_{\max }$ is positive for events travelling to the east. Also shown are the distance for which the events are observed along the slope, and their sign, positive for positive temperature gradients. Whilst the range of possible angles is broad, most of the events travel east, contrary to the surge direction, and half have negative gradients, slightly smaller the proportion found in Fig. 3. These 'fast' events travel, on average, $147 \mathrm{~m}$ along the slope.

\section{Discussion}

Internal surges travel cyclonically around the boundaries of lakes, westward in the area of these observations. This study demonstrates the presence of propagating disturbances, most of which cannot be caused by instability or advected by the flow, in the period following the passage of a surge. Large negative temperature gradients are observed, characteristic of internal waves as they steepen on reflection from a slope. Twice as many propagate to the east, the direction opposite to the surge, than propagate in a westerly direction.

The discussion leading to Eq. (1) continues to hold if the incident internal waves are propagating locally as wave rays rather than modes (see Thorpe, 1999a)
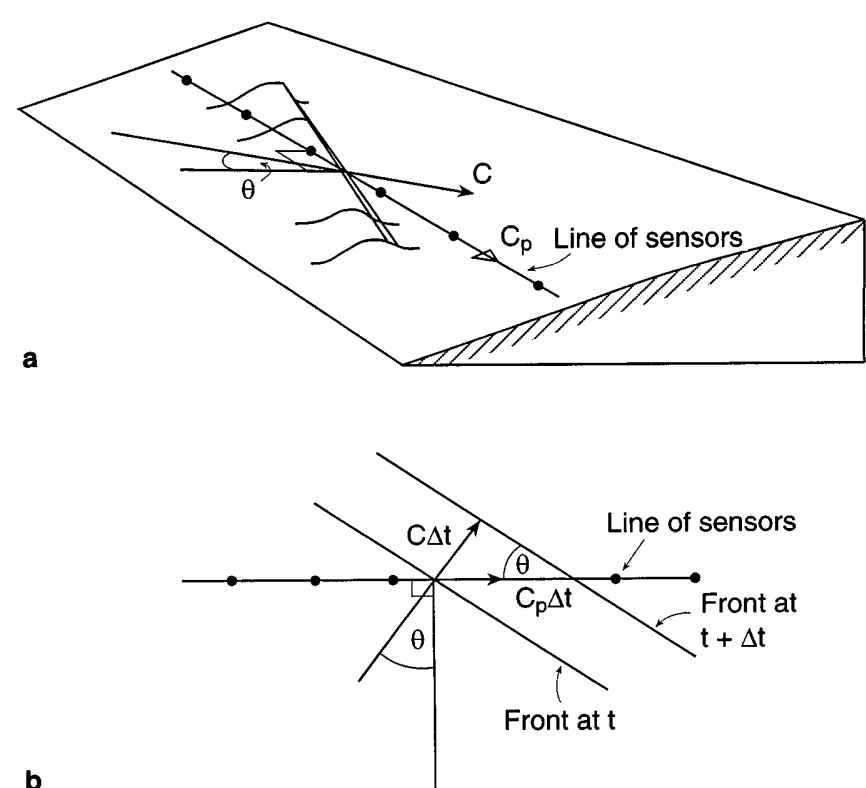

Fig. 7a, b. Sketch showing a isopycnal surfaces moving across the array of sensors lying on the slope and $\mathbf{b}$ the geometry. $\Delta t$ is a small time increment, during which the front advances forward a distance $c \Delta t$, and along the slope a distance $c_{p} \Delta t . \theta$ is the angle of incidence 


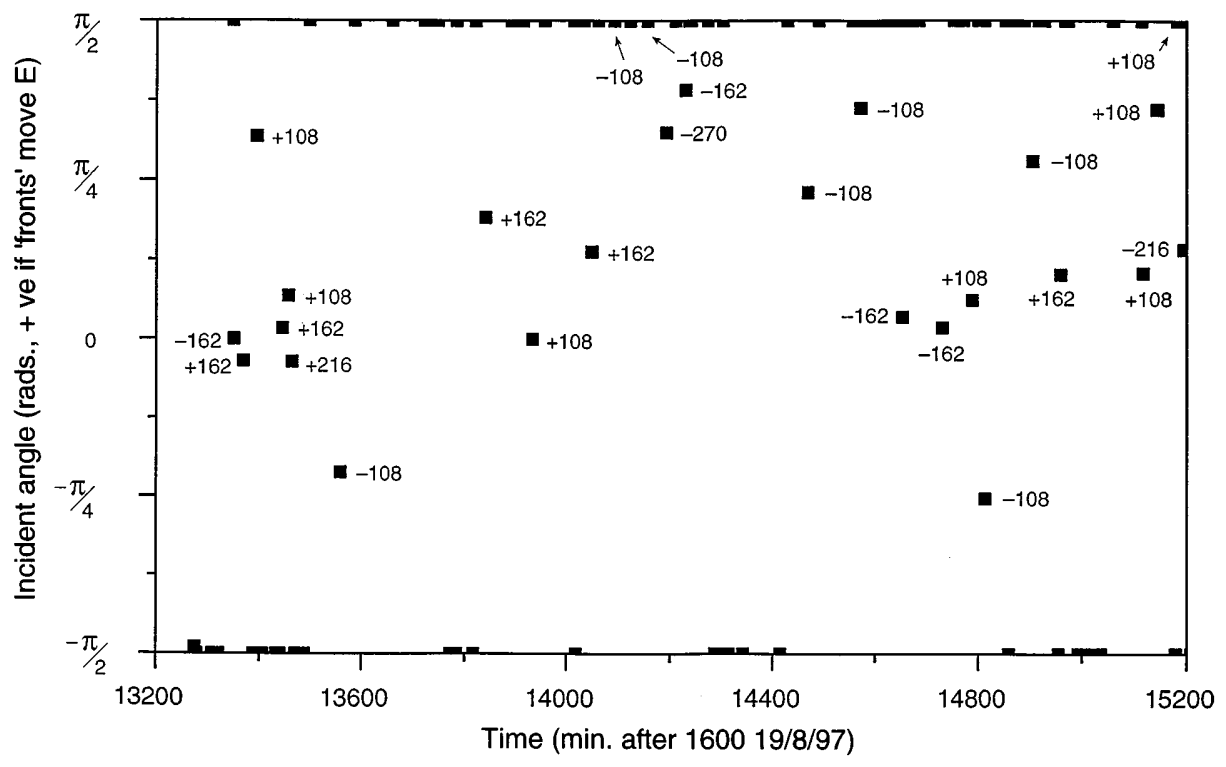

Fig. 8. The maximum angle of incidence of features (e.g. waves) producing events moving along the slope. The numbers indicate the event distance along the slope $(\mathrm{m})$ and the sign denotes that of the temperature derivative associated with each event provided the phase speed is taken as the horizontal component. Internal waves of frequency $\sigma$ travelling in a direction of incidence, $\theta$, to a uniform slope inclined at angle $\alpha$ to the horizontal in uniformly stratified fluid of buoyancy frequency, $N$, and Coriolis frequency, $f$ have constant phase lines on the boundary inclined to isobaths at angle $\psi$ given by

$\psi=\cot ^{-1}(\cos \alpha \cot \theta+\cot \beta \operatorname{cosec} \theta \sin \alpha)$,

where $\beta=\sin ^{-1}\left[\left(\sigma^{2}-f^{2}\right) /\left(N^{2}-f^{2}\right)\right]^{1 / 2}$ (Thorpe, 1999b), This reduces to $\psi=\theta$ on a horizontal bottom when $\alpha=0$. The discussion leading to Eq. (1) depends however on the speed of the crest line along the slope. This is determined by the horizontal phase speed and $\theta$, not $\psi$. If the phase speed, $c$, is taken as the horizontal component of the wave phase speed vector, $\sigma / \mathrm{K}$, where $\mathrm{K}$ the horizontal wave number of an internal wave, the along-slope wave number is $l=\mathrm{K} \sin \theta$ so the alongslope speed is $c_{p}=\theta / l=\theta / \mathrm{K} \sin \theta=c / \sin \theta$, as before. (Both $\sigma$ and $l$ are conserved on reflection.)

The more frequent large negative temporal gradients shown in Fig. 3 may be explained by the presence of fronts associated with incident internal waves as described in the first section; cold denser water flows upslope, forming a front as the wave advances. More small positive gradients are however found than small negative gradients. It is suggested that as the denser colder water returns downslope it becomes unstable, developing Kelvin-Helmholtz billows which, being carried downslope in the mean returning flow, advect past the sensors. The 'braids' between billows are sites of abrupt changes from cold to warmer water. Their passing the fixed sensors may give rise to small, but appreciable, positive gradients in temperature, leading to the bias observed at small gradients. This is consistent with a suggestion offered by Thorpe et al. (1991) to explain the observed positive skewness during the downslope phase of the internal tide on the Porcupine Bank in the northeast Atlantic. In absolute values the size of the mean skewness $(-0.05)$ is however smaller than the mean value $(-0.35)$ found in the oceanic measurements, perhaps because of the finer resolution here.

Whilst sets of minilogger temperature sensors deployed on long lines of rope laid along the bottom provide a useful means of making spatially distributed measurements of temperature near the bed, there are several limitations to the experiment:

1. The temporary burial of sensors and consequent increase in the time to respond to temperature changes is easily remedied by attaching buoyant material to the loggers (whilst retaining sensor exposure) and suspending them above the bed line on short lines attached to weights.

2. Some of the events may well have been falsely identified as a consequence of the local random generation of high gradients at neighbouring sensors which happened at constant time delay, but which were not linked by being associated with a propagating front. The frequency of such occurrences cannot be determined from the data, but it is possible to estimate the probability of random events having chance 'alignment' in time. A model data set was simulated in which events with the same mean separation and length as the real events occur at random times at each sensor. The frequency of the lengths of events thus predicted are shown by the dashed line in Fig. 5b. The model predicts a greater proportion of events with small lengths than are observed. More significantly, a much greater proportion of long events are observed than are predicted by the model. This indicates a greater degree of organisation in the observations than would occur simply by chance, even though some sensors were responding only slowly to temperature changes, so that the length of some events would have been underestimated. The marked directional bias towards eastward motion of events through the array seen in Figs. 6 and 8 is further strong evidence against a majority having chance alignment. A separation smaller than $54 \mathrm{~m}$ might 
have resolved some of the uncertainty in recognising connected events.

3. The ADCM is outside the span of the temperature sensors and the current field over the array is therefore not known accurately. More observations of currents are desirable. Obliquely incident internal waves breaking on the sloping boundaries of lakes generate alongslope currents which may reach a few $\mathrm{cm} / \mathrm{s}$ in speed (Thorpe, 1999b). Whilst the currents measured within the lower $9 \mathrm{~m}$ of the water column do vary by such amounts, the record length is too short to establish any correlation even with the direction of propagation of the observed waves. A future objective is to estimate the along-slope convergence and divergence in the boundary layer which results from internal wave breaking.

A bias towards westward propagation had been expected; wave trains are often found to follow a surge in its cyclonic path around the lake (e.g. Thorpe and Jiang, 1998). Whilst the spectral analysis provides some evidence of westward propagation at $0.6 \mathrm{cyc} \mathrm{h}^{-1}$ near the critical frequency where wave amplification is likely (Eriksen, 1982, 1985), the higher frequency waves coherent at sensor separations of $54 \mathrm{~m}$ and the negative derivative events show clear eastward propagation. Unlike the event analysis, the spectra provide little evidence of coherent wave propagation over distances greater than $54 \mathrm{~m}$.

The most likely interpretation of the observations is that waves near the critical frequency are propagating from the southeast quadrant, so that their phase travels westward along the east-west orientated slope, but that the higher frequency waves are from the southwest quadrant, producing eastward propagating fronts at the slope, and more of them since the wave period is higher. The data however suggest that the large time-derivative events occur intermittently, possibly as groups of higher waves arrive and steepen at the slope, much as do surface waves at the edge of the familiar surf zone on the seashore.

Acknowledgements. SAT is grateful for funds from LRH/EPFL to take part in this study.

Topical Editor D.J. Webb thanks A. Stigebrandt and J.M. Huthnance for their help in evaluating this paper.

\section{References}

Banks, W. H. H., P. G. Drazin, and M. B. Zaturska, On the normal modes of parallel flow of inviscid stratified fluid, J. Fluid Mech., 75, 149-171, 1976.

Dunkerton, T. J., D. P. Delisi, and M.-Pascale Lelong, Alongslope current generated by obliquely incident internal gravity waves, Geophys. Res. Letts. 25, 3871-3874, 1998.

Eriksen, C. C., Observations of internal wave reflection off sloping bottoms, J. Geophys. Res., 87, 525-538, 1982.

Eriksen, C. C., Implications of ocean bottom reflection for internal wave spectra and mixing, J. Phys. Oceanogr, 15, 1145-1156, 1985.

Eriksen, C. C., Internal wave reflection and mixing at Fieberling Guyot, J. Geophys. Res., 103, 2977-2994, 1998.
Ledwell, J. R., and B. M. Hickey, Evidence of enhanced boundary mixing in the Santa Monica Basin, J. Geophys. Res., 100, 20, 665-20 679, 1995.

Lemmin, U., R. Jiang, and S. A. Thorpe, Finestructure dynamics of stratified waters near a sloping boundary of a lake, in Physical processes in lakes and oceans, Ed. J.Imberger, AGU Coastal and Esturine Series, 54, 461-474, 1998.

MacIntyre, S., K. M. Flynn, R. Jellison, and J. R. Romero, Boundary mixing and nutrient fluxes in Mono Lake, CA, Limnol. Oceanogr., in press., 1999.

Orlanski, I., and K. Bryan, Formation of the thermocline step structure by large-amplitude internal gravity waves, J. Geophys. Res., 74, 6975-6983, 1969.

Slinn, D. N., and J. J. Riley, Turbulent mixing in the oceanic boundary layer caused by internal wave reflection from sloping terrain., Dyn. Atmos. Oceans, 24, 51-62, 1996.

Thorpe, S. A., Internal gravity waves, $\mathrm{PhD}$ Thesis, University of Cambridge, UK, 1966.

Thorpe, S. A., On the reflection of a train of finite amplitude internal waves from a uniform slope, J. Fluid Mech., 178, 279302, 1987.

Thorpe, S. A., Thermal fronts generated by internal gravity waves reflecting from a slope, J. Phys. Oceanogr., 22, 105-108, 1992.

Thorpe, S. A., Turbulence in the stratified and rotating World Ocean, Theoret. Comput. Fluid Mech., 11, 171-181, 1998.

Thorpe, S. A., Fronts formed by obliquely reflecting internal waves at a sloping boundary, J. Phys. Oceanogr., (in press) 1999a.

Thorpe, S. A., The generation of alongslope currents by breaking internal waves, J. Phys. Oceanogr., 29, 29-38, 1999b.

Thorpe, S. A., and R. Jiang, Estimating internal waves and diapycnal mixing from conventional mooring data in a lake, Limnol. Oceanogr., 43, 936-945, 1998.

Thorpe, S. A., M. Curé, and M. White, The skewness of temperature derivatives in oceanic boundary layers, J. Phys. Oceanogr., 21, 428-433, 1991.

Thorpe, S. A., J. M. Keen, R. Jiang, and U. Lemmin, Highfrequency internal waves in Lake Geneva, Philos. Trans. R. Soc. London, A, 354, 237-257 1996.

Thorpe, S. A., U. Lemmin, C. Perrinjacquet, and I. Fer, Observations of the thermal structure of a lake using a submarine, Limnolog. Oceanogr, (in press) 1999 to appear in volume 44 part 6 , pages not yet known. 